\title{
A Rapid Bioluminescence Method for Quantifying Bacterial Adhesion to Polystyrene
}

\author{
By M. J. HARBER,* RUTH MACKENZIE AND A. W. ASSCHER \\ Department of Renal Medicine, Welsh National School of Medicine, K.R.U.F. Institute, Royal \\ Infirmary, Cardiff CF2 1SZ, U.K.
}

(Received 30 March 1982; revised 5 July 1982)

\begin{abstract}
Bioluminescence ATP analysis has been used to assess bacterial adhesion with hydrophobic polystyrene tubes as the attachment surface. The assay was performed at $37^{\circ} \mathrm{C}$ and $\mathrm{pH} 6.8$ with a $10 \mathrm{~min}$ incubation period. A variation of more than 200 -fold was observed in the adherence capacity of 34 urinary isolates of Escherichia coli, and organisms could be classified as strongly or weakly adherent. All strains capable of strong adhesion possessed both type 1 fimbriae and flagella, and maximum adhesion was expressed during the exponential growth phase. Attachment was in all cases virtually eliminated by addition of $2.5 \%(\mathrm{w} / \mathrm{v}) \mathrm{D}$-mannose to the incubation buffer. Conversely, strains which were deficient in type 1 fimbriae or flagella, or both, were weakly adherent during all phases of growth. There was no correlation between adherence of $E$. coli to polystyrene and adherence to buccal or uroepithelial cells, but there was a significant association with adherence to uromucoid $(P<0.002)$.
\end{abstract}

\section{INTRODUCTION}

It is widely believed that the adherence of bacteria to mucosal surfaces is an important first stage in the pathogenesis of many infectious diseases. A variety of biological systems have been used to study and measure bacterial adherence in vitro, most methods using exfoliated or freshly isolated epithelial cells as the attachment surface. There is some uncertainty, however, whether sloughed-off cells are truly representative of intact epithelia, while a high level of colonization of epithelial cells with indigenous organisms can often be a practical problem. Furthermore, the presence of uromucoid (Tamm-Horsfall protein) in preparations of uroepithelial cells can present a serious source of error since bacterial adherence to human uroepithelial cells is mediated predominantly by mannose-resistant (MR) fimbriae, while adhesion to mucus (which may coat the cell surface) is associated with mannose-sensitive (MS) type 1 fimbriae (Ørskov et al., 1980a; Chick et al., 1981).

Recent studies have shown that fresh urinary bacterial isolates are non-fimbriate and nonadherent to buccal and uroepithelial cells (Harber et al., 1982a), results which indicate that fimbrial-mediated adhesion is not a virulence factor for bacteria within the lumen of the urinary tract. However, these observations do not preclude a role for adhesion in tissue invasion within the renal parenchyma which can occur once the pathogens have passed through the urinary tract (Harber et al., 1982b). Some MR fimbriae recognize as a receptor for attachment a carbohydrate component of the $\mathbf{P}$ blood group antigens which are commonly found on the surface of epithelial cells (Källenius et al., 1980; Leffler \& Svanborg Edén, 1980). These adhesins, which have been designated $\mathbf{P}$ fimbriae, appear to be a marker of virulence for Escherichia coli in early episodes of symptomatic pyelonephritis (Väisänen et al., 1981; Källenius et al., 1981).

MS fimbriae appear to play no part in the attachment of uropathogens to human uroepithelial cells (Ørskov et al., 1980a; Chick et al., 1981), but an important distinction must be made

Abbreviations: MR, mannose-resistant; MS, mannose-sensitive. 
between humans and animal models in this respect since several reports have demonstrated mannose-sensitive bacterial adherence to rat bladder cells (Aronson et al., 1979) and rodent bladders in vivo (Fader et al., 1979; Chick \& Asscher, 1980). There are, in addition, two aspects in which bacterial adherence mediated by MS fimbriae may be of clinical significance. Firstly, mannose-sensitive adherence may be an important factor in the host-parasite relationship within tissues as MS fimbriae facilitate attachment of bacteria to professional phagocytes in the absence of antibody and complement (Silverblatt et al., 1979; Mangan \& Snyder, 1979; BarShavit et al., 1980). Secondly, the ability of uromucoid to trap MS fimbriate bacteria may represent an important host defence mechanism within the urinary tract (Ørskov et al., 1980 b), and since this adherence cannot be measured directly, due to the impracticability of quantifying urinary mucus, an indirect method of study is desirable.

Because of the variable nature of biological surfaces some workers have used solid surfaces of glass or polystyrene to study bacterial attachment since these materials provide more stable and better defined surfaces. Purified type 1 fimbriae adhere by their tips to polystyrene latex particles (Brinton, 1965), and hence polystyrene would appear to be a highly suitable material for quantifying bacterial adhesion mediated by type 1 fimbriae, and for studying the surface properties of the bacterial cell which are relevant to the attachment process. The adherence of organisms to glass and polystyrene has been quantified by staining washed preparations and relating the absorbance of the stain to bacterial numbers (Fletcher, 1976; Rutter \& Abbott, 1978), while methods for measuring bacterial adherence to epithelial cells rely on the use of radio-labelled cultures or on direct microscopic examination (Chick et al., 1981). A more simple and potentially more accurate and sensitive method for determining cell numbers is to measure extractable ATP using the firefly bioluminescence system (Harber, 1982). Indeed, this technique has already been used successfully to determine viable cell mass in dental plaque (Robrish et al., 1978; Distler et al., 1980).

In this communication we present a simple and rapid bioluminescence method for measuring bacterial adherence using hydrophobic polystyrene tubes as the attachment surface. The method is used to assess the properties of the bacterial cell which influence attachment of a series of urinary isolates of $E$. coli to polystyrene, and to compare the ability of these organisms to adhere to polystyrene with their ability to adhere to isolated epithelial cells and uromucoid.

\section{METHODS}

Organisms. A total of 34 urinary isolates of E. coli were selected for study. Strains 7, 10, 12, 20, 23, 44, 49, 56, 57, $63,88,101,103$ and 168 were obtained from the Department of Microbiology, University of Newcastle-uponTyne, U.K.; strains 297, 385, 417, 434, 436, 439, 461, 469, 478, 504 and 517 were obtained from the Department of Medicine, Charing Cross Hospital, London, U.K.; strains KS69, KS70, KS71, ER2, NK1 and T1 were obtained from the National Bacteriological Laboratory, Stockholm, Sweden; and strains KV, SC and WJ were isolated in our own laboratory. The bacteria were stored on slopes of Dorset egg medium and before use were subcultured on five consecutive days at $37^{\circ} \mathrm{C}$ in static Oxoid nutrient broth no. 2 to obtain full expression of type 1 fimbriation. Siliconized glassware was used for the subcultures to minimize attachment of the organisms to the walls of the containers.

Buffer systems. Phosphate-buffered saline (PBS) pH 6.8 was used in all adherence experiments; this contained $\left(\mathrm{g}^{-1}\right): \mathrm{KH}_{2} \mathrm{PO}_{4} 3.45, \mathrm{Na}_{2} \mathrm{HPO}_{4} 4.45, \mathrm{NaCl} 5.00$ and $\mathrm{KCl} 0.20$. When required, D-mannose was added at a concentration of $2 \cdot 5 \%(\mathrm{w} / \mathrm{v})$. PBS covering a range of $\mathrm{pH}$ values from $5 \cdot 3$ to 8.3 was used to determine the optimum $\mathrm{pH}$ for bacterial adherence. The buffer for the bioluminescence analysis was $25 \mathrm{~mm}$-HEPES buffer pH 7.75 containing 2 mM-EDTA.

Extraction of bacterial ATP. ATP was extracted from suspensions of bacteria in PBS by vortex mixing $100 \mu \mathrm{l}$ bacterial suspension with $100 \mu$ Lumac NRB reagent (nucleotide releasing reagent for bacteria; Sterilin, U.K.) for $10 \mathrm{~s}$ followed by the immediate addition of $800 \mu \mathrm{l}$ HEPES buffer (Fig. 1). A similar procedure was employed for the extraction of ATP from adherent bacteria in polystyrene tubes but using $40 \mu \mathrm{l}$ of a mixture of equal volumes of NRB and PBS (NRB/PBS reagent) in order to maintain the same ratio of NRB : PBS that was present when extracting ATP from bacterial suspensions in PBS. These extracts were vortex mixed for $10 \mathrm{~s}$ and then treated with $160 \mu$ l HEPES buffer.

Bioluminescence ATP assay. Extracted ATP was measured using an LKB Luminometer 1250 after adding $100 \mu \mathrm{l}$ LK B ATP-monitoring reagent (firefly luciferin/luciferase) to a $200 \mu \mathrm{l}$ sample. Light emission was registered in $\mathrm{mV}$ on a digital display unit. 


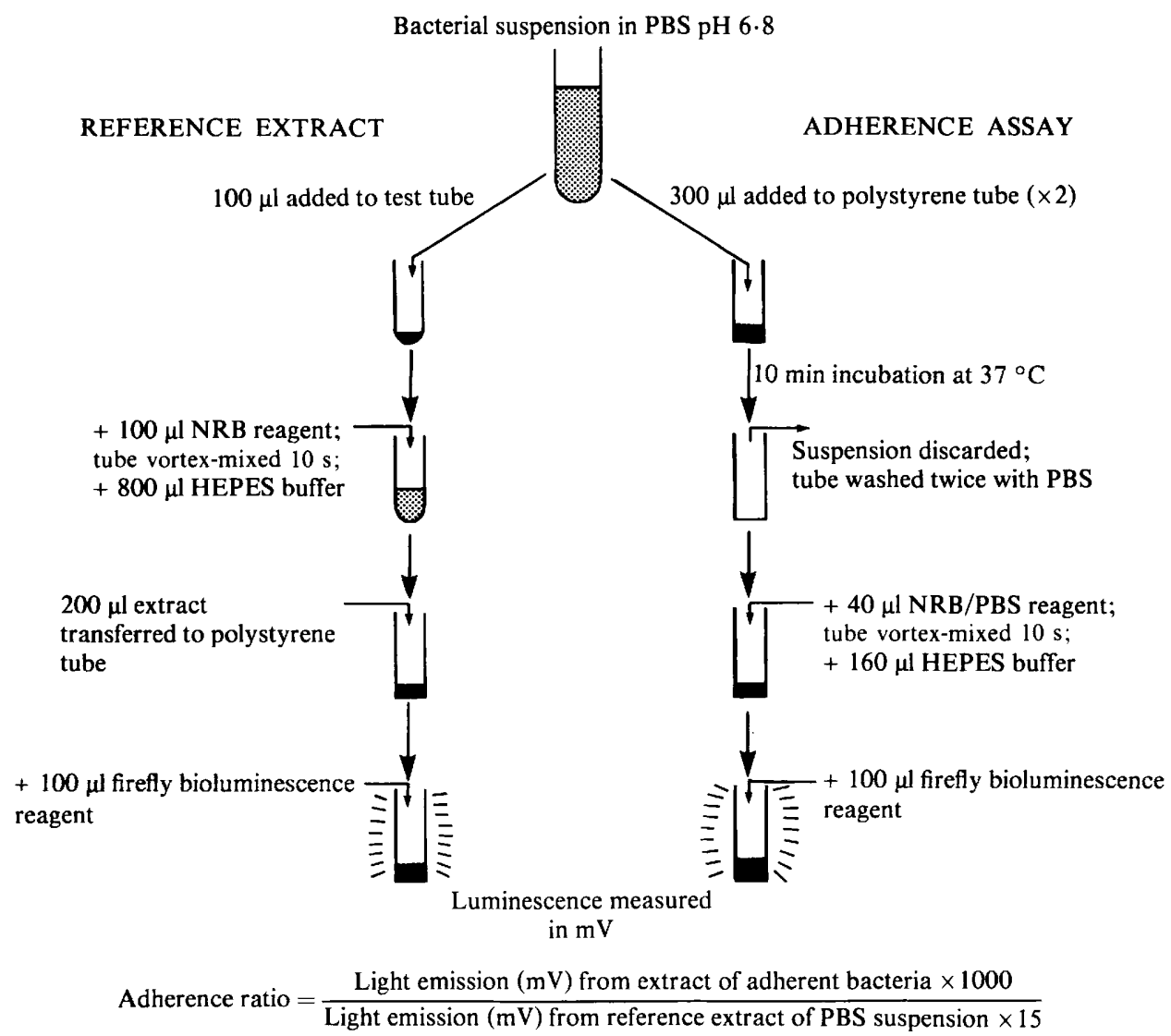

Fig. 1. Flow diagram of the bioluminescence/polystyrene tube adherence assay.

Polystyrene tubes. The tubes used for the adherence assay were those designed for use with the LKB Luminometer 1250 (available from Clinicon, U.K.), these being hydrophobic (non-wettable) polystyrene. A crosshatching in the base of the tubes conveniently increased the internal surface area. All operations were performed in a single tube.

Adherence assay. A flow diagram of the bioluminescence/polystyrene tube adherence testing system is presented in Fig. 1. The fifth overnight subculture in static nutrient broth for each test organism was diluted 1/10 in PBS to yield a suspension containing about $1 \times 10^{8}$ c.f.u. $\mathrm{ml}^{-1}$. Duplicate $300 \mu \mathrm{l}$ samples from this suspension were placed into polystyrene tubes and incubated for $10 \mathrm{~min}$ in a waterbath at $37^{\circ} \mathrm{C}$. The bacterial suspensions were then aspirated using a water pump fitted with a trap containing disinfectant, and the tubes washed twice with $1 \mathrm{ml}$ PBS delivered from a repeating dispenser. Adherence assays were set up and the polystyrene tubes subsequently washed at $1 \mathrm{~min}$ intervals so that up to 10 samples, each in duplicate, could be handled conveniently in any given experiment. Bacterial ATP was extracted and measured as described above.

Calculation of adherence ratio. The amount of ATP in a $200 \mu \mathrm{l}$ sample of an extract of the original bacterial suspension in PBS served as the reference point for calculating the ratio of the number of bacteria adhering to the polystyrene tubes to the total number of organisms present in the PBS suspension. The number of adherent bacterial cells per thousand of the population in the original PBS suspension was calculated as follows:

Mean $\mathrm{mV}$ reading of extract of bacteria adhering to tubes $\times 1000$

$\mathrm{mV}$ Reading of extract of bacterial suspension in PBS $\times 15$ (volume correction factor)

Effect of bacterial numbers on adhesion. Serial dilutions of broth cultures of four representative organisms (strains 23, 49, 56 and 297) were prepared in PBS containing $10 \%(\mathrm{v} / \mathrm{v})$ nutrient broth and tested for adherence in the normal manner.

Effect of centrifugation and nutrient broth on adhesion. The third overnight subculture in static nutrient broth for each of six strains $(23,49,56,103,168$ and 297) was centrifuged for $15 \mathrm{~min}$ at $1400 \mathrm{~g}$ and the pellets were 
resuspended in PBS and then diluted $1 / 10$ in PBS containing $0 \%, 10 \%$ or $20 \%(\mathrm{v} / \mathrm{v})$ nutrient broth. These dilutions were tested for adherence and the results compared with parallel cultures treated by the normal procedure.

Effect of bacterial growth phase on adhesion. Samples were taken at regular intervals from the fifth subculture in static nutrient broth for two representative strains (23 and 49). These samples were diluted $1 / 10$ in PBS and tested for adhesion to polystyrene tubes by the normal procedure. The phase in the growth cycle was assessed by $A_{560}$.

Effect of inhibition of flagella synthesis on adhesion. Six adherent flagellate strains (12,23, 168, 297, 385 and 504) were subcultured four times in static nutrient broth followed by a single subculture in broth containing $4 \mathrm{mM}$ EDTA to inhibit flagella synthesis (Weiser et al., 1972). The ability of these organisms to adhere to polystyrene was then compared with that of parallel cultures grown in the absence of EDTA.

Effect of prolonging the assay incubation period on the adhesion of fimbriate, non-flagellate organisms. When broth cultures of bacteria which had been diluted $1 / 10$ in PBS were incubated at $37^{\circ} \mathrm{C}$ for more than 10 min an increase in extractable ATP was observed which was attributed to bacterial growth. This factor was allowed for whenever adhesion tests were performed using prolonged incubation periods by incubating samples of the bacterial suspensions in PBS under identical conditions to the test samples, and using the total extractable ATP level in these reference tubes as the denominator in the formula for calculating the adherence ratio. The adherence of four type 1 fimbriate but non-flagellate strains $(434,439,517$ and $\mathrm{KS} 69)$ was measured using this procedure after 10, 60 and $150 \mathrm{~min}$ incubation, and two type 1 fimbriate and flagellate strains (297 and 504) were studied similarly after subculture in the presence and absence of 4 mM-EDTA.

Reference biological adherence methods. Human buccal cells and uroepithelial cells, obtained from healthy individuals, were used for comparison with the polystyrene tube method for adherence of the 34 test organisms. These cells were washed three times in PBS and then resuspended to a concentration of approximately $10^{5} \mathrm{ml}^{-1}$. A mixture of $10^{5}$ epithelial cells and $10^{8}$ bacteria in $2 \mathrm{ml} \mathrm{PBS}$ was incubated with rotation for $1 \mathrm{~h}$ at $37^{\circ} \mathrm{C}$, and then vacuum filtered using a $5 \mu \mathrm{m}$ Nuclepore polycarbonate membrane. The filter pad was washed and pressed on to a glass microscope slide, and the resulting imprint was stained and examined microscopically. The mean number of bacteria adhering per cell was determined from the counts for 30 epithelial cells, and adherence to the uromucoid, which was always present in preparations of uroepithelial cells, was noted simultaneously. Adherence to mucoid could not be quantified, but since organisms which adhered to mucoid did so in very large numbers, a score of 1 was given to those strains which showed such definite attachment, and a score of 0 was given to those which did not, in order to allow statistical analysis of the observations. Full details of these reference methods have been published in a separate communication (Chick et al., 1981).

Comparison of polystyrene tube method with reference biological methods. The 34 test strains of $E$. coli were examined after five consecutive daily subcultures in nutrient broth for adherence of each to polystyrene, buccal cells, uroepithelial cells and uromucoid, and also for agglutination of guinea-pig and human erythrocytes. All reactions were performed both in the presence and absence of $2.5 \%$ D-mannose. Samples were also taken simultaneously for morphological inspection by electron microscopy.

Electron microscopy. Pellets of each organism were resuspended in a stain of $2 \%(\mathrm{w} / \mathrm{v})$ phosphotungstic acid containing $0.2 \%(\mathrm{w} / \mathrm{v}) \mathrm{BSA}$ and adjusted to $\mathrm{pH} 7.0$ with $\mathrm{NaOH}$. The bacteria were then taken on to carbon-coated collodion films on copper grids and examined using a Philips 300 electron microscope. All cultures contained a mixture of fimbriate and non-fimbriate cells and the percentage of cells with fimbriae was noted in each case. Most cultures also contained bacterial cells which possessed flagella, and the percentage of cells with flagella was recorded similarly for each organism. All these observations were made independently by the microscopist.

Haemagglutination reactions. The ability of the organisms to agglutinate guinea-pig erythrocytes (inhibited by Dmannose), or human erythrocytes in the presence of D-mannose, was used to differentiate between possession of MS type 1 fimbriae and MR fimbriae, respectively, by strains for which fimbriae could be detected by electron microscopy. Erythrocytes from citrated whole blood were in each case washed twice with PBS pH 6.8 and resuspended in this buffer to a concentration of $3 \%(\mathrm{v} / \mathrm{v})$. One drop was then mixed with one drop of a suspension of $10^{9}$ bacteria $\mathrm{ml}^{-1}$ in PBS alone or PBS containing $2.5 \%$ D-mannose on a glass slide with gentle rocking at ambient temperature (about $20^{\circ} \mathrm{C}$ ). Agglutination was observed visually and scored as described in Table 2 .

\section{RESULTS}

Precision, recovery and sensitivity data. The intra-assay precision for the polystyrene tube adhesion testing method expressed in terms of coefficient of variation for the analysis of 12 replicate samples was $\pm 8.5 \%$, while the recovery of 10 pmol of exogenous ATP per tube was 104 $\pm 3 \%(n=12)$. The mean coefficient of variation for the analysis of the adhesion of 21 strains on each of three consecutive days when full expression of type 1 fimbriation appeared to have been achieved (the third, fourth and fifth subcultures in static nutrient broth) was $\pm 36.3 \%$. The 


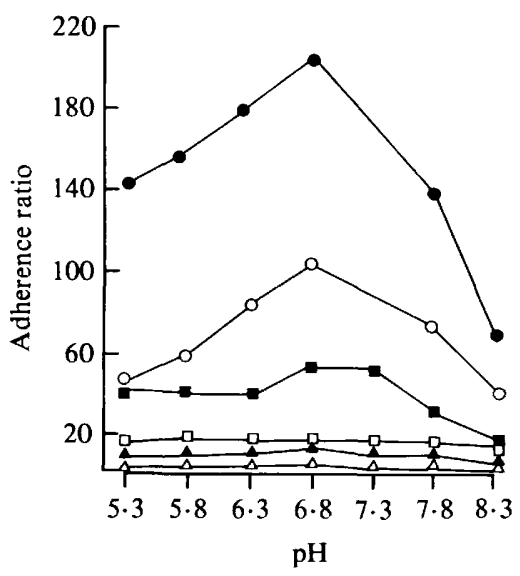

Fig. 2. Effect of $\mathrm{pH}$ on the adhesion of six strains of $E$. coli to polystyrene. The strains used were: 297 (O), $23(\bigcirc), 103(\square), 49(\square), 56(\Delta)$ and $44(\triangle)$.

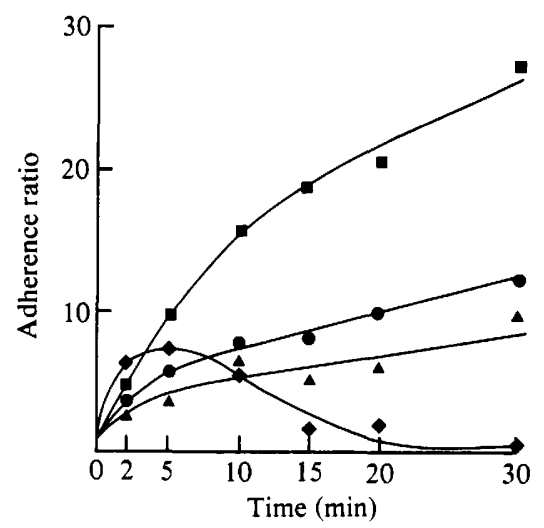

Fig. 3. Effect of incubation time and temperature on the adherence of one representative $E$. coli strain (436). The assay tubes were incubated at $4{ }^{\circ} \mathrm{C}(\boldsymbol{A}), 20^{\circ} \mathrm{C}(\boldsymbol{\odot}), 37^{\circ} \mathrm{C}(\boldsymbol{\mathbb { Q }})$ and $56^{\circ} \mathrm{C}(\bullet)$.

limit of detection for the bioluminescence assay was 0.02 pmol ATP in a $200 \mu 1$ sample, this being equivalent to about $5 \times 10^{5} \mathrm{E}$. coli $\mathrm{ml}^{-1}$ PBS suspension or about $1 \times 10^{4}$ adherent bacteria per tube.

Effect of $\mathrm{pH}$ and phosphate on adhesion. The optimum $\mathrm{pH}$ for the adherence of strongly adherent strains of $E$. coli was $6 \cdot 8$, while weakly adherent strains were unaffected by variations in pH (Fig. 2). Phosphate per se had no influence on the adhesion process.

Effect of temperature on adhesion. Adherence to polystyrene increased slowly but steadily on prolonged incubation at $4{ }^{\circ} \mathrm{C}$, and the rate of attachment increased with temperature. However, adherence was completely inhibited after a few minutes incubation at $56^{\circ} \mathrm{C}$, and an incubation temperature of $37^{\circ} \mathrm{C}$ appeared to be optimal. Data for an organism possessing both type 1 fimbriae and flagella (strain 436) are illustrated in Fig. 3.

Effect of bacterial numbers on adhesion. For any investigated strain, almost identical adherence ratios were obtained in adherence assays using PBS suspensions containing from $6 \times 10^{6}$ to $5 \times$ $10^{8}$ c.f.u. $\mathrm{ml}^{-1}$. Data for the four strains tested were applied to a modification of the Langmuir adsorption isotherm (Fletcher, 1977) but were found not to fit the isotherm equation.

Effect of centrifugation and nutrient broth on adhesion. Centrifugation of cultures produced a detrimental effect on bacterial adhesion, reducing the adhesive capacity of the six strains tested by $40-70 \%$ (Table 1 ). This was the case irrespective of whether the centrifuged pellets were 
Table 1. Adherence ratios for six $E$. coli strains before and after centrifugation

Treatment of bacterial cells

Uncentrifuged control; diluted in PBS

Centrifuged and resuspended in broth; diluted in PBS

Centrifuged and resuspended in PBS; diluted in PBS

Centrifuged and resuspended in PBS; diluted in $10 \%$ broth

Centrifuged and resuspended in PBS; diluted in $20 \%$ broth

Adherence ratios of strains of $E$. coli

\begin{tabular}{ccccccc}
\hline $\begin{array}{c}\text { Strain } \\
23\end{array}$ & $\begin{array}{c}\text { Strain } \\
49\end{array}$ & $\begin{array}{c}\text { Strain } \\
56\end{array}$ & $\begin{array}{c}\text { Strain } \\
103\end{array}$ & $\begin{array}{c}\text { Strain } \\
168\end{array}$ & $\begin{array}{c}\text { Strain } \\
297\end{array}$ & $\begin{array}{c}\text { Difference } \\
\text { from control* }\end{array}$ \\
38 & 45 & 29 & 9 & 17 & 37 & - \\
25 & 14 & 5 & 7 & 9 & 26 & $P<0.02$ \\
7 & 17 & 12 & 3 & 7 & 12 & $P<0.01$ \\
21 & 12 & 11 & 5 & 6 & 26 & $P<0.02$ \\
22 & 9 & 6 & 5 & 7 & 25 & $P<0.02$
\end{tabular}

* Adherence ratios for each centrifuged treatment group were compared with those of the uncentrifuged control group using Student's paired $t$-test. This experiment was performed with the third overnight subculture of each strain in static nutrient broth in which expression of type 1 fimbriae was sub-maximal for strains 103 and 297.

resuspended in nutrient broth or PBS, the former producing no significant influence on adhesion even when present in the final incubation suspension at a concentration of $20 \%$.

Effect of bacterial growth phase on adhesion. The ability of strains possessing both type 1 fimbriae and flagella to adhere to polystyrene increased during exponential growth to reach a peak towards the end of the exponential phase, and declined markedly in the stationary phase. However, organisms lacking either type 1 fimbriae or flagella or both were weakly adherent irrespective of the phase of growth.

Adherence ratios and effect of D-mannose on adhesion. Adherence data and other relevant observations are presented in Table 2. A variation of more than 200-fold was observed in the adherence ratios of the 34 test strains when assayed for adherence to polystyrene, even in the stationary phase of growth, and two groups could be identified. Sixteen strains with an adherence ratio $<10$ were classified as being weakly adherent, while the remaining 18 strains which showed an adherence ratio $\geqslant 10$ were designated strongly adherent, this adherence being strongly inhibited by $2.5 \% \mathrm{D}$-mannose. The mannose sensitivities for the weakly adherent group could not be determined accurately due to the low level of adherence, but about half of these strains appeared to be adherent in a mannose-sensitive manner and half in a mannose-resistant manner.

Role of fimbriae and flagella in adhesion. Bacterial adhesion to polystyrene showed no association with the presence of MR fimbriae as assessed by the agglutination of human erythrocytes in the presence of mannose (Table 3). However, all 18 strains which were strongly adherent produced mannose-sensitive haemagglutination of guinea-pig erythrocytes, and since electron microscopy showed all these strains to be fimbriate they were judged to possess MS fimbriae. Electron microscopy also revealed that a major proportion of individual cells $(\geqslant 40 \%)$ for all but one of the 18 organisms possessed flagella as well as fimbriae. Conversely eight other MS fimbriate strains which showed only weak adhesion to polystyrene were sparsely flagellate or lacked these organelles entirely (Table 3 ).

Effect of inhibition of flagella synthesis on adhesion. Electron microscopy confirmed that EDTA-treated cultures were non-flagellate. The absence of flagella was associated with virtual abolition of the ability of the organisms to adhere to polystyrene (Fig. 4). Fimbrial synthesis was unaffected by growth in EDTA broth since all strains still produced strong agglutination of guinea-pig erythrocytes, while EDTA per se had no inhibitory effect in the adhesion assay.

The adherence of non-flagellate strains increased on prolonged incubation but still remained at a low level in comparison to values recorded for flagellate strains (Table 4).

Comparison of the polystyrene tube method with reference biological methods. All but one of the 34 strains of $E$. coli showed a significant level of adherence to buccal epithelial cells; data for adherence to uroepithelial cells have been published elsewhere (Chick et al., 1981). There was no association between adherence to either buccal or uroepithelial cells and possession of flagella $(P>0 \cdot 1$, Mann-Whitney $U$ test $)$. Furthermore, there was no correlation between attachment 
Table 2. Haemagglutination reactions, electron microscopy observations and adherence data for 34 strains of $E$. coli

\begin{tabular}{|c|c|c|c|c|c|c|}
\hline \multirow[b]{2}{*}{$\begin{array}{l}\text { Strain } \\
\text { no. }\end{array}$} & \multicolumn{2}{|c|}{ Haemagglutination reactions* } & \multicolumn{3}{|c|}{ Adherence to polystyrene } & \multirow{2}{*}{$\begin{array}{l}\text { Adherence to } \\
\text { uromucoid } \\
\text { without } \\
\text { D-mannoseł }\end{array}$} \\
\hline & $\begin{array}{c}\text { Guinea-pig } \\
\text { erythrocytes } \\
\text { without D-mannose }\end{array}$ & $\begin{array}{c}\text { Human } \\
\text { erythrocytes } \\
\text { with D-mannose }\end{array}$ & $\begin{array}{c}\text { Flagella present } \\
\text { (EM observation) } \dagger\end{array}$ & & & \\
\hline
\end{tabular}

\begin{tabular}{|c|c|c|c|c|c|}
\hline 7 & - & ++ & - & 1 & 1 \\
\hline 10 & - & - & - & 5 & 2 \\
\hline 12 & +++ & - & + & 41 & 2 \\
\hline 20 & - & - & - & 3 & 4 \\
\hline 23 & +++ & - & + & 83 & 9 \\
\hline 44 & +++ & - & - & 5 & 1 \\
\hline 49 & +++ & +++ & + & 29 & 3 \\
\hline 56 & +++ & +++ & + & 21 & 2 \\
\hline 57 & - & +++ & - & 2 & 2 \\
\hline 63 & +++ & +++ & + & 137 & 9 \\
\hline 88 & - & +++ & - & 3 & 3 \\
\hline 101 & - & + & + & 4 & 3 \\
\hline 103 & +++ & ++ & + & 38 & 4 \\
\hline 168 & +++ & - & + & 24 & 4 \\
\hline 297 & +++ & - & + & 176 & 5 \\
\hline 385 & +++ & + & + & 11 & 3 \\
\hline 417 & +++ & + & - & 19 & 1 \\
\hline 434 & +++ & + & - & 2 & 1 \\
\hline 436 & +++ & +++ & + & 19 & 1 \\
\hline 439 & +++ & - & - & 1 & 1 \\
\hline 461 & +++ & - & + & 17 & 3 \\
\hline 469 & +++ & + & + & 50 & 3 \\
\hline 478 & +++ & + & - & 3 & 1 \\
\hline 504 & +++ & - & + & 65 & 4 \\
\hline 517 & +++ & + & - & 5 & 2 \\
\hline KS69 & +++ & ++ & - & 3 & 1 \\
\hline $\mathrm{KS} 70$ & +++ & + & + & 41 & 5 \\
\hline KS71 & +++ & +++ & + & 12 & 2 \\
\hline ER2 & +++ & + & - & 2 & 1 \\
\hline NK 1 & +++ & +++ & - & 2 & 0 \\
\hline $\mathrm{T} 1$ & - & + & - & 5 & 4 \\
\hline $\mathrm{KV}$ & +++ & - & + & 13 & 4 \\
\hline $\mathrm{SC}$ & - & +++ & - & 2 & 3 \\
\hline WJ & +++ & ++ & + & 25 & 2 \\
\hline
\end{tabular}

* Symbols: +++ , rapid, strong reaction; ++ , moderate reaction; + , slow, weak reaction; and - , no observed haemagglutination.

$\dagger$ All strains possessed fimbriae except numbers 7 and 20 . Strains were scored + for flagella if $\geqslant 40 \%$ of individual cells were flagellate, and - if $<40 \%$ of individual cells were flagellate.

$\ddagger$ A score of 1 was given to strains which showed definite attachment to uromucoid and a score of 0 to strains which did not.

Table 3. Analysis of the adherence of 34 strains of E. coli to polystyrene tubes

No. showing

Sub-group

No. of strong adherence Median Statistical analysis

MR fimbriae present

MR fimbriae absent

strains $\quad($ ratio $\geqslant 10)$ adherence ratio on individual values*

MS fimbriae present

MS fimbriae absent

$\begin{array}{rrrl}23 & 11 & 5 & P>0.1 \\ 11 & 7 & 17 & \\ 26 & 18 & 19 & P<0.01 \\ 8 & 0 & 3 & \\ 18 & 17 & 27 & P<0.001 \\ 16 & 1 & 3 & \\ 17 & 17 & 29 & P<0.001 \\ 17 & 1 & 3 & \end{array}$

Flagellate cells sparse or absent $(<40 \%) \quad 16$

MS fimbriae present and flagella abundant 17

MS fimbriae absent and flagella sparse or absent

* Adherence data were analysed by the Mann-Whitney $U$ test. 


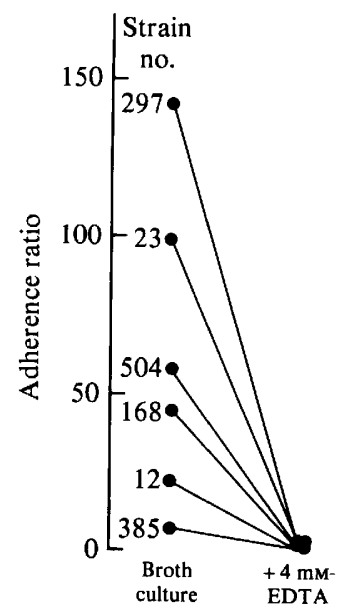

Fig. 4. Abolition of the adhesion of six strains of $E$. coli following subculture in nutrient broth containing 4 mm-EDTA.

Table 4. Adherence ratios following prolonged incubation of non-flagellate strains of $E$. coli in polystyrene tubes

Values in parentheses indicate adherence ratios recorded after growth in nutrient broth containing $4 \mathrm{mM}-\mathrm{EDT} A$ to inhibit flagella synthesis.

\begin{tabular}{ccccc}
\multirow{2}{*}{ Strain type } & $\begin{array}{c}\text { Strain } \\
\text { no. }\end{array}$ & \multicolumn{1}{c}{ Incubation time (min) } \\
Non-flagellate strains & KS69 & 0 & 60 & 150 \\
& 434 & 0 & 3 & - \\
& 439 & 1 & 4 & - \\
Flagellate controls & 517 & 5 & 9 & 7 \\
& 297 & $142(2)$ & $266(7)$ & $293(18)$ \\
& 504 & $58(2)$ & $63(9)$ & $73(25)$
\end{tabular}

of the strains to polystyrene and adhesion to either buccal cells or uroepithelial cells, this being the case irrespective of whether the whole series of organisms was considered or only the 18 strains which showed strong adherence to polystyrene $(P>0 \cdot 1$, Mann-Whitney $U$ test).

The individual adherence ratios obtained in the polystyrene tube assay for strains which adhered to uromucoid were compared with the ratios for strains which did not, using the MannWhitney $U$ test. The median values were 19.1 and 2.6 for the mucoid-adherent and non-adherent groups respectively, and the analysis indicated a significant association between adherence to polystyrene and adherence to mucoid $(P<0.002)$.

A correlation was found between bacterial adherence to uromucoid and possession of flagella $(P<0.02$, Mann-Whitney $U$ test $)$, but this appeared to be an epiphenomenon since there was also a significant association between possession of flagella and possession of MS fimbriae $(P<$ $0.05, \chi^{2}$ test) which indicated that expression of these surface characteristics was coincidental.

As reported previously (Chick et al., 1981) adherence to uromucoid was significantly associated with MS fimbriation, 24 of 26 MS fimbriate strains adhering to mucoid whereas all strains without MS fimbriae were non-adherent $(P<0.001$, Mann-Whitney $U$ test). A total of 17 of the 24 strains which adhered to mucoid also adhered strongly to polystyrene. All but one of these 17 possessed flagella as well as MS fimbriae, while the remaining seven strains which adhered to mucoid but which were only weakly adherent to polystyrene lacked flagella. One anomalous strain with both MS fimbriae and flagella adhered to polystyrene but not to uromucoid. 
The bioluminescence assay presented above provides a rapid and sensitive method for quantifying bacterial adherence to solid surfaces. A very wide variation was observed in the ability of different strains of $E$. coli to adhere to polystyrene, and a number of important factors have been identified which affect the adhesive characteristics of bacteria in this test system. Although the observed inter-assay variation was high $( \pm 36 \cdot 3 \%)$ this did not affect the classification of any of the strains as strongly or weakly adherent. It is considered that the day to day variation in adherence ratio may be attributed largely to variability in the expression of surface bacterial characteristics in different broth cultures. Maximum expression of type 1 fimbriae appeared to be achieved after three to five subcultures in static nutrient broth, but electron microscopy revealed that the percentage of fimbriate cells for each strain could vary from day to day even after such repeated subculture. The high inter-assay variation does not indicate poor reproducibility of the adherence assay per se, since the intra-assay variation was relatively low $( \pm 8 \cdot 5 \%)$.

The rate of attachment of bacteria to the side-walls and base of a polystyrene tube might be expected to be governed largely by Brownian movement and sedimentation resulting in chance interaction of the cells with the polystyrene surface, while attachment per se might be expected to be mediated largely by non-specific processes of adsorption. However, data for the adherence of four strains which possessed both type 1 (MS) fimbriae and flagella tested over a wide range of dilutions failed to fit a modification of the Langmuir adsorption isotherm. This suggested that biological phenomena are important in determining the rate of adhesion instead of, or in addition to, physico-chemical factors.

One factor which is well documented as playing a major role in the adherence of Gramnegative bacteria to solid surfaces is the possession of fimbriae. No association was found between adherence to polystyrene and possession of MR fimbriae, but there was a very significant correlation between adherence data and possession of type 1 (MS) fimbriae. Type 1 fimbriate $E$. coli attached strongly to polystyrene tubes in a mannose-sensitive manner, whereas all strains devoid of type 1 fimbriae were weakly adherent.

It was apparent that other factors must be involved with adhesion in addition to type 1 fimbriae since eight strains which possessed these organelles showed only a low level of adherence. The explanation for this finding came from the observation that cultures of all organisms showing strong adherence to polystyrene contained a high proportion of cells which possessed flagella as well as type 1 fimbriae. With only one exception both types of organelle were found to be required for a high level of attachment. The essential involvement of flagella in the adhesion process was confirmed by the fact that adherent strains could be rendered nonadherent simply by inhibiting flagella synthesis by growth in EDTA broth. Damage to or loss of flagella is the most likely explanation for the marked detrimental effect which centrifugation of broth cultures had on adhesion, free flagella being a common finding during electron microscopic examination of centrifuged bacterial cultures. Furthermore, the effects of variation in growth phase on adhesion may also be largely attributable to changes in the motility of cells during growth in batch culture since motility is likely to decline with the onset of stationary phase (Fletcher, 1977, 1979).

Motility may be involved with adhesion in three possible ways. Firstly, it may simply increase the chances of a bacterial cell coming into contact with the attachment surface; secondly, motility may enable bacteria to overcome the electrostatic potential barrier which exists between surfaces of like charge; thirdly, flagella per se may be directly involved in mediating attachment. Guentzel \& Berry (1975) considered that the most likely explanation for the association they observed between virulence of Vibrio cholerae and motility was the increased chance of association between bacterial cells and the intestinal mucosa. Conversely, Fletcher (1979) speculated that adherence of a motile Pseudomonas sp. to polystyrene might be facilitated by an ability to overcome electrostatic forces of repulsion, while there is some evidence for a direct holdfast role for flagella in the attachment of Gram-negative bacilli (Meadows, 1971) and vibrios (de Boer et al., 1975) to solid surfaces. In the present study a small increase in adherence was observed with non-flagellate or de-flagellated strains of $E$. coli on prolonged incubation in 
polystyrene tubes, but the level of adhesion remained low in comparison with that of the flagellate strains. This would suggest that flagella play a more active role in the attachment process than simply increasing the statistical chance of cell-surface contact.

Flagella and fimbriae are both proteinaceous structures and the dramatic inhibition of adhesion produced at $56^{\circ} \mathrm{C}$ is almost certainly due to protein denaturation in either or both of these types of organelle. Active motility is an energy-requiring process, hence $37^{\circ} \mathrm{C}$ was found to be the optimum temperature for adherence. However, the fact that a slow but progressive increase in adherence was observed at $4{ }^{\circ} \mathrm{C}$ suggests that the forces of attraction which mediate attachment once cell-surface contact has been established are not dependent on expenditure of energy. It has been suggested that hydrophobic interactions associated with masking of cell surface potential by fimbriae might influence the adherence characteristics of enteropathogenic strains of $E$. coli (Smyth et al., 1978). Hydrophobic interactions are likely to be involved with bacterial adhesion to polystyrene, but it would appear that intimate cell-surface contact must first be promoted through the action of flagella.

No correlation was found between adhesion of $E$. coli to polystyrene and adhesion to uroepithelial or buccal epithelial cells. This was not a surprise finding, however, since attachment to polystyrene was observed to be mediated by type 1 (MS) fimbriae whereas adherence to human uroepithelial cells is mediated by MR fimbriae (Ørskov et al., 1980 a ; Chick et al., 1981). Buccal cells appear to provide a relatively non-specific attachment surface compared with uroepithelial cells or polystyrene, only one of the 34 test strains being nonadherent in this system. One obvious difference in the attachment of bacteria to the biological cell surfaces compared with attachment to polystyrene is that adherence is maximal with stationary phase cultures using epithelial cells, whereas maximum adherence to polystyrene is achieved with bacteria in the exponential growth phase. The most likely explanation for this difference lies with the involvement of bacterial motility in adhesion, flagella being an essential factor when polystyrene is the attachment surface but of no importance with the three biological assays. However, it is of interest to note in this context that motility has been reported recently to promote the attachment of Salmonella typhimurium to HeLa cells (Jones et al., 1981).

Bacterial adhesion to both polystyrene and uromucoid was mediated by type 1 (MS) fimbriae, and a significant association was observed between adherence of our $E$. coli strains to these two surfaces $(P<0.002)$. However, this correlation masked one important difference in that whereas 24 of the 26 strains with type 1 fimbriae adhered to uromucoid, only those strains possessing both type 1 fimbriae and flagella (with one exception) adhered to polystyrene. This distinction was still apparent even when the incubation period for the polystyrene tube assay was extended to $1 \mathrm{~h}$ or more. Hence the polystyrene tube method may give an indication of the susceptibility of motile type 1 fimbriate bacteria to be trapped by uromucoid, but it would appear to have no application to non-motile organisms. However, it could be of interest to determine whether or noi there is any correlation between the adherence of pathogenic bacteria to polystyrene and their susceptibility to phagocytosis, since type 1 fimbriae are capable of mediating attachment of non-opsonized bacteria to the surface membranes of phagocytic cells (Silverblatt et al., 1979; Mangan \& Snyder, 1979; Bar-Shavit et al., 1980), while a recent report has demonstrated bacterial motility to be an important factor in the phagocytosis of a variety of Gram-negative bacilli by murine macrophages (Tomita et al., 1981). Furthermore, it is considered that the bioluminescence detection system described in this communication could be applied to the study of mechanisms of bacterial adhesion using certain biological as well as nonbiological attachment surfaces, or with polystyrene coated with appropriate 'receptor' substances.

We are grateful to Professor M. Sussman, Department of Microbiology, University of Newcastle-upon-Tyne, Dr A. P. Roberts, Department of Medicine, Charing Cross Hospital, London and Dr G. Källenius, National Bacteriological Laboratory, Stockholm, Sweden for kindly supplying test organisms used in this study. 


\section{REFERENCES}

Aronson, M., Medalia, O., Schori, L., Mirelman, D., Sharon, N. \& OfeK, I. (1979). Prevention of colonization of the urinary tract of mice with Escherichia coli by blocking of bacterial adherence with methyl $\alpha$-D-mannopyranoside. Journal of Infectious Diseases 139, 329-332.

Bar-Shavit, Z., Goldman, R., Ofek, I., SHARON, N. \& MIRELMAN, D. (1980). Mannose-binding activity of Escherichia coli: a determinant of attachment and ingestion of the bacteria by macrophages. Infection and Immunity 29, 417-424.

Brinton, C. C., JR (1965). The structure, function, synthesis and genetic control of bacterial pili and a molecular model for DNA and RNA transport in Gram-negative bacteria. Transactions of the New York Academy of Sciences 27, 1003-1054.

ChICK, S. \& Asscher, A. W. (1980). Studies on the significance of bacterial adherence in experimental urinary tract infection. In Pyelonephritis, vol. $I V$, Urinary Tract Infections, pp. 67-71. Edited by H. Losse, A. W. Asscher \& A. E. Lison. Stuttgart \& New York: Georg Thieme Verlag.

Chick, S., Harber, M. J., Mackenzie, R. \& Asscher, A. W. (1981). Modified method for studying bacterial adhesion to isolated uroepithelial cells and uromucoid. Infection and Immunity 34, 256-261.

De Boer, W. E., Golten, C. \& Scheffers, W. A. (1975). Effects of some physical factors on flagellation and swarming of Vibrio alginolyticus. Netherlands Journal of Sea Research 9, 197-213.

Distler, W., KrönCKe, A. \& MAUReR, G. (1980). Adenosine triphosphate content of human dental plaque as a measure of viable cell mass. Caries Research 14, 265-268.

Fader, R. C., Avots-Avotins, A. E. \& Davis, C. P. (1979). Evidence for pili-mediated adherence of Klebsiella pneumoniae to rat bladder epithelial cells in vitro. Infection and Immunity 25, 729-737.

FLeTCHER, M. (1976). The effects of proteins on bacterial attachment to polystyrene. Journal of General Microbiology 94, 400-404.

FLETCHER, M. (1977). The effects of culture concentration and age, time, and temperature on bacterial attachment to polystyrene. Canadian Journal of Microbiology 23, 1-6.

Fletcher, M. (1979). The attachment of bacteria to surfaces in aquatic environments. In Adhesion of Micro-organisms to Surfaces, pp. 87-108. Edited by D. C. Ellwood, J. Melling \& P. Rutter. London, New York \& San Francisco: Academic Press.

Guentzel, M. N. \& BERRY, L. J. (1975). Motility as a virulence factor for Vibrio cholerae. Infection and Immunity 11, 890-897.

Harber, M. J. (1982). Applications of luminescence in medical microbiology and haematology. In Clinical and Biochemical Luminescence, pp. 189-218. Edited by L. J. Kricka \& T. J. N. Carter. New York: Marcel Dekker.

HaRber, M. J., Chick, S., Mackenzie, R. \& Asscher, A. W. $(1982 a)$. Lack of adherence to epithelial cells by freshly isolated urinary pathogens. Lancet i, 586588.

Harber, M. J., Mackenzie, R. K. \& Asscher, A. W. $(1982 b)$. Bacterial adherence and the urinary tract. Lancet i, 1352-1353.
Jones, G. W., Richardson, L. A. \& Uhlman, D. (1981). The invasion of HeLa cells by Salmonella typhimurium: reversible and irreversible bacterial attachment and the role of bacterial motility. Journal of General Microbiology 127, 351-360.

Källenius, G., Möllby, R., Svenson, S. B., WiNBERG, J. \& HULTBERG, H. (1980). Identification of a carbohydrate receptor recognized by uropathogenic Escherichia coli. Infection 8 (supplement 3), S288S293.

Källenius, G., Möllby, R., Svenson, S. B., Helin, I., Hultberg, H., Cedergren, B. \& Winberg, J. (1981). Occurrence of P-fimbriated Escherichia coli in urinary tract infections. Lancet ii, 1369-1372.

Leffler, H. \& Svanborg Edén, C. (1980). Chemical identification of a glycosphingolipid receptor for Escherichia coli attaching to human urinary tract epithelial cells and agglutinating human erythrocytes. FEMS Microbiology Letters 8, 127-134.

Mangan, D. F. \& SNYder, I. S. (1979). Mannosesensitive interaction of Escherichia coli with human peripheral leukocytes in vitro. Infection and Immunity 26, 520-527.

Meadows, P. S. (1971). The attachment of bacteria to solid surfaces. Archiv für Mikrobiologie 75, 374-381.

ØRSKOV, I., ØRSKOV, F. \& BIRCH-ANDERSON, A. (1980a). Comparison of Escherichia coli fimbrial antigen $F_{7}$ with type 1 fimbriae. Infection and Immunity 27, 657-666.

Ørskov, I., Ferencz, A. \& ØRSKov, F, (1980 b). Tamm-Horsfall protein or uromucoid is the normal urinary slime that traps type 1 fimbriated Escherichia coli. Lancet i, 887.

Robrish, S. A., KeMP, C. W. \& Bowen, W. H. (1978). Use of extractable adenosine triphosphate to estimate the viable cell mass in dental plaque samples obtained from monkeys. Applied and Environmental Microbiology 35, 743-749.

Rutter, P. R. \& AввotT, A. (1978). A study of the interaction between oral streptococci and hard surfaces. Journal of General Microbiology 105, 219226.

Silverblatt, F. J., Dreyer, J. S. \& Schauer, S. (1979). Effect of pili on susceptibility of Escherichia coli to phagocytosis. Infection and Immunity 24, 218223.

SMYth, C. J., Jonsson, P., Olsson, E., Söderlind, O., Rosengren, J., HuERTÉN, S. \& WadströM, T. (1978). Differences in hydrophobic surface characteristics of porcine enteropathogenic Escherichia coli with or without $\mathrm{K} 88$ antigen as revealed by hydrophobic interaction chromatography. Infection and Immunity 22, 462-472.

Tomita, T., Blumenstock, E. \& Kanegasaki, S. (1981). Phagocytic and chemiluminescent responses of mouse peritoneal macrophages to living and killed Salmonella typhimurium and other bacteria. Infection and Immunity 32, 1242-1248.

VÄIsÄnen, V., Elo, J., Tallgren, L. G., Siltonen, A., Mäkelä, P. H., Svanborg EdÉn, C., Källenius, G., Svenson, S. B., Hultberg, H. \& Korhonen, T. (1981). Mannose-resistant haemagglutination and $P$ antigen recognition are characteristic of Escherichia coli causing primary pyelonephritis. Lancet ii, 13661369. 
Weiser, R., Moffat, D. B., Wimpenny, J. C., Asscher, A. W. \& Sussman, M. (1972). Ethylenediamine tetra-acetic acid (EDTA) induced morphological changes in Proteus mirabilis. Zentralblatt für
Bakteriologie, Parasitenkunde, Infektionskrankheiten und Hygiene (Abteilung I, Originale A: Medizinische Mikrobiologie und Parasitologie) 222, 52-56. 